\title{
COLLABORATIVE COMMUNITIES AS A SELLING POINT? FROM COMMUNITY-DRIVEN TO SERVICE-PURPOSED COWORKING SPACES
}

\begin{abstract}
Coworking spaces emerged in the mid-2000s as collaborative workplaces that actively supported teleworkers and self-employed knowledge workers who shared various (work) environments to interlace themselves in supportive networks, tackle isolation, positively influence well-being, and collaboratively participate in knowledge-sharing activities. However, with the swift popularisation of the coworking model by 2020, newly established flexible office spaces have begun to refer to themselves as community-based workplaces even though they lacked the capacity to support their users' interactions and collaborative work. Therefore, the purpose of the paper is to explore how coworking spaces have transformed from community-based environments to a flexible place of work where establishing a collaborative community is not an organisational priority. The following exploratory research investigates a sample of 13 coworking spaces in Prague, the Czech Republic, and considers their capacity for supporting interactions and collaborative processes between their users. The results uncovered significant differences between coworking spaces, their spatial designs, the presence of mediation mechanisms, and the frequency of interactions between users, and suggest that the handful of sampled coworking environments misuse the notion of community. In that context, the following study indicates that contemporary coworking spaces can revert to community washing to deliberately pursue economic self-interest rather than support decentralised peer-to-peer exchange that would lead to developing a coworking community.
\end{abstract}

Key words: coworking, shared workspaces, community-washing, mediation.

\footnotetext{
* Marko OREL, Will BENNIS, Prague University of Economics and Business, Department of Entrepreneurship, W. Churchill Sq. 4, 13067 Prague 3, Czechia, e-mails: marko.orel@vse.cz, will. bennis@vse.cz, ORCiDs: https://orcid.org/0000-0002-1931-7310, https://orcid.org/0000-00027481-6438 


\section{INTRODUCTION}

The last two decades have brought considerable alternations in how knowledge workers tend to work, interact with one another, and cooperate on mutual tasks. These changes have led to the popularisation of on-demand office environments that have swiftly morphed into highly flexible workspaces, becoming increasingly used by remote workers, the self-employed, and others who conduct their work on an individualised basis. The design of these offices has continued to be based on spatial openness enhancing the ability of individuals to interact and form social relationships. Commonly referred to as coworking environments, these human-centred work spaces aim to support the creation of supportive networks that are regularly identified as collaborative communities of work (Merkel, 2015; Rus and Orel, 2015; Gardenitsch et al., 2016; Bianchi et al., 2018; Bouncken and Reuschl, 2018).

The first contemporary coworking spaces emerged in 2005 as a direct response to the socio-economic challenges of the time (Spinuzzi, 2012; Rus and Orel, 2015). Self-employed individuals, solo entrepreneurs, and remote workers, who frequently felt the isolation due to previously working from the seclusion of their homes, organised group work sessions in a shared environment to avoid alienation (Orel and Almeida, 2019), maintain an adequate level of work/life balance (Weijs-Perrée et al., 2017), and interconnect in supportive work-based communities (Rus and Orel, 2015; Bouncken and Aslam, 2019). Due to its positive outcomes for daily users, the coworking model saw a fast popularisation and increase in numbers at the turn of the century, bringing coworking environments to urban and rural areas (Kovács and Zoltán, 2017). Coworking spaces have spread to local cafés (Green, 2014; Lukman et al., 2018), formed within libraries (Lumley, 2014; Schopfel et al., 2015), became adopted by traditional offices (Sargent et al., 2018) and seen other alternations with their pre-pandemic numbers doubling on an annual basis (Orel and Dvouletý, 2020).

Coworking spaces have been widely recognised as places that are co-constructing a sense of community (Garrett et al., 2017) that follows the work activities of their members (Blagoev et al., 2019) and provides a caring environment for both personal growth and optimal delivery of work outputs (Mirel, 2015). However, the increased popularisation of the coworking concept has brought noticeable changes to the inceptive model. Coworking spaces, commonly independently-run, have not only grown bigger in size and capacity and subsequently morphed into serviced office centres (Mayerhoffer, 2020), but also changed fundamentally in terms of how they intend to connect individuals by supporting horizontal encounters between them (Orel and Dvouletý, 2020). Multilocation and multinational coworking sites such as WeWork and Regus (IWG group) shifted their focus to accommodate a larger number of individuals and corporate teams of 
workers (Bouncken et al., 2018; Yang et al., 2019; Mayerhoffer, 2020) instead of focussing on a smaller and more interconnected userbase of individual knowledge workers (Gandini, 2016; Waters-Lynch and Potts, 2017).

While some of the recent studies have explored coworking spaces and their capacity to form collectives with the ability to identify common goals (Blagoev et al., 2019), co-create value (Bouncken et al., 2018) and host various types of collaborative communities (Spinuzzi et al., 2019), it is still not entirely clear how coworking spaces utilise the presence of their moderators to build a supportive network within, and how coworking environments have hybridised due to the said swift popularisation of the model in recent years. What is more, there is an uncertainty whether the growth in ranks of coworking spaces causes a shift from community-driven to service-purposed workplaces that can attract a larger number of individual users and corporate teams, while lacking the capacity and tools to interconnect them in active collaborative communities. The latter also calls for the debate whether specific coworking spaces purposely revert to community-washing, intending to deliberately pursue economic self-interest rather than support decentralised peer-to-peer exchange that would lead to developing a coworking community.

With that in mind, the following study seeks to answer these questions and investigates a sample of 13 coworking spaces in the city of Prague, the Czech Republic. First, the paper explores the concept and characteristics of coworking spaces and the development of communities by overviewing relevant past studies with annotated literature review. Second, the paper further builds on the data collected using the mixed-method approach, combining the qualitative approach of semi-structured interviewing and non-obstructive participant observation to determine the collective capacity of the sampled coworking spaces. Finally, a survey conducted among coworking space users is used to measure the level of perceived support for interaction between users that may or may not result in the presence of a coworking community. The findings are subsequently analysed and cross-compared with results which suggest that a proportion of the studied coworking spaces indeed misused the notion of community and disguised service-based workspaces as community-driven coworking environments.

\section{LITERATURE REVIEW AND THEORETICAL DEVELOPMENT}

\subsection{The characteristics of coworking spaces}

Coworking spaces help break geographic and institutional barriers to open collaboration (Rus and Orel, 2015) by co-constructing a sense of supportive community (Garrett et al., 2017) that is managed by moderators such as community 
managers (Gregg and Lodato, 2018; Bouncken et al., 2018; Spinuzzi et al., 2019; Haubrich, 2021) using mediation mechanisms (Brown, 2017) to employ a community-based governance model (Castilho and Quandt, 2017). Mediation mechanisms most commonly take the form of facilitation tools (e.g., matchmaking events, conversation starters, etc.) that support the development of group creativity (Brown, 2017) and both formal and informal collaboration between coworking space users (Orel and Almeida, 2019). By most accounts, a well-planned mediation additionally promotes more significant innovation (Surman, 2013; Schmidt et al., 2014; Marchegiani and Arcese, 2018) and efficiency (Butcher, 2018), enabling the biggest talents for a particular project to come together quickly and affordably with as little interference as possible (Constantinescu and Devisch, 2018). They thus break institutional barriers because they are shared by people who do not work for the same organisation (Spinuzzi, 2012), commonly resulting in an availability of non-binding relationships and collaboration forms (Bouncken and Reuschl, 2018).

Additional benefits linked to using coworking facilities are the availability of non-materialistic, emotional support (Gerdenitsch et al., 2016; Cheah and Ho, 2019; Hall et al., 2019), typically in the form of solidarity as a by-product of professional cooperation between coworking space users (Bianchi et al., 2018), and the reduction of alienation and isolation (De Peuter et al., 2017; Orel and Almeida, 2019) that result in the improvement of users' work/life balance (Gandini, 2016; Orel, 2019). Moreover, the usage of coworking spaces is repeatedly connected with increased work-related productivity that may lead to new product development or the emergence of additional project opportunities (Ross and Ressia, 2015; Cabral and Van Winden, 2016; Leclercq-Vandelannoitte and Isaac, 2016; Bueno et al., 2018).

Individual knowledge workers tend to use a coworking space over a home-office or neighbourhood café because of the opportunities for knowledge exchange with other workspace users through horizontal interactions (Kubátová, 2014; Parrino, 2015; Akhavan et al., 2019; Bouncken and Aslam, 2019). They tend to seek a new perspective on labour processes, given the requirement for constant innovation (Merkel, 2015). As such, coworking spaces are often identified as go-to places for their support of social and open innovation (Aguiton and Cardon, 2008; Capdevila, 2014; Schmidt et al., 2014; Fuzi et al., 2018).

Considering these defining factors, coworking spaces are widely understood as working environments for individual users and smaller teams of knowledge workers who share knowledge resources, workspace equipment, and ideas to positively affect their labour processes and the quality of daily lives. From its modest start in communal and grass-root movements back in 2005 (Avdikos and Iliopoulou, 2019; Merkel, 2019), the coworking model has recently become widely adopted by corporate environments (Green, 2014; Rosati et al., 2016; Arora, 2017; Sargent et al., 2018; Pyszka, 2019; Mayerhoffer, 2020), seeing increased investment trends (Gauger et al., 2019) and the development of workspace brands with multiple business locations (e.g., WeWork, IWG, Industrious LLC, etc.) 
These trends are causing the coworking model to undergo transformative changes shifting the initial focus from community-driven collaborative platforms to purposed productivity-orientated workspaces (Orel and Dvouletý, 2020). However, there are indications that their managers are camouflaging these environments of work as communal offices with a distinctive narrative of human-centred workspaces, with users frequently finding limited opportunities for becoming actively involved in supportive communities.

\subsection{Coworking community as a selling point}

We argue that there is a rising trend amongst contemporary coworking spaces and their operators to project community and collaboration principles only to attract their clientele. At the same time, their workspaces in practice lack sufficient mediation support to steer encounters into the development of dynamic social networks of cooperation. It is no surprise when one considers the recent trends within sharing economies. Hawlitschek et al. (2018) has reported that 78 per cent of sharing-acquainted adult individuals agree that the sharing economy can build stronger and more capable communities. The accessibility to assets within sharing and collaborative communities can be an appealing idea for a broad segment of society (Avram et al., 2017) and can be transformed into a selling point (Price and Belk, 2016).

As contemporary coworking spaces are supposedly built on a communal foundation where individual users can find supportive co-users (Garrett et al., 2017; Rus and Orel, 2015; Brown, 2017), they can become an appealing course to attracting clients to establish a swift userbase. However, what putative coworking spaces provide, with respect to community and support, varies widely and sometimes they offer nothing at all (Gandini, 2016; Merkel, 2017). Therefore, in parallel with the sharewashing or crowdwashing phenomenon, where sharing platforms deliberately pursue economic self-interest rather than sharing resources (Schor, 2016; Penz et al., 2018), community-washing can be used to sell non-existing communities in shared workspaces.

From another angle, community-washing can be established to improve and whitewash the reputation of selected workspaces and organisations behind them and build a positively perceived brand (Hill, 2019). It seems that instant communities are widely built on the bro culture that transitions the values from a culture of informality into a modern office environment, making coworking spaces appealing to individuals because of the prevalent uncertainty and risks of independent work (Merkel, 2019).

However, the same individuals may find upon entering these coworking spaces empty shell spaces where the communities are non-existent or built upon weak relationships that do not meet expectations. Interactions on the horizontal level 
(i.e., encounters between regular users) may be solely formal with interactions on the vertical level (i.e., encounters between regular users and workspace operators) minimised to the rudimental client-customer degree, leaving individuals unable to knit meaningful relationships that would result in anticipated emotional support (Bianchi et al., 2018) or functional relationships that would result in new business opportunities (Cabral and Van Winden, 2016).

The likelihood of expected collaboration diminished and promoted collaborative workspaces are demoted to office environments with shared infrastructure but without benefits upon which the initial coworking space were formed. These challenges call for a study that would assess the plausibility of coworking environments being mistakenly or deliberately projected as communal centres and to understand various practices used to steer the relationships between users within these workspaces.

\section{METHODOLOGICAL FRAMEWORK}

The purpose of the paper is, therefore, to support or possibly reject the hypothetical claim that contemporary coworking environments have transformed into service-purposed (i.e., primarily focusing on providing services related to the workspace usage) shared office spaces that are not necessarily community-based (i.e., mainly focusing on developing interactions and subsequent relations between individual users that result in the development of collaborative communities), and have limited capacity in supporting horizontal interactions between workspace users. With that, the study seeks to answer the following three research questions. First, how coworking environments differ concerning a) their spatial arrangements, and b) the presence of mediation personnel and mediation mechanisms that support the development of interactions between coworking space users. Second, how coworking spaces have transformed from community-driven to service-purposed workplaces. And third, whether contemporary coworking spaces can disguise their service-purposed roles by misusing the notion of collaborative community.

To provide full or partial answers to these questions, the study has formed its basis on a) an annotated review of the relevant literature, b) short semi-structured interviews with coworking space managers, c) qualitative non-obstructive participant observation of different coworking environments with regard to (i) their spatial configurations, (ii) the presence of mediation personnel, and (iii) the frequency of horizontal interactions, and d) quantitative surveys of different coworking space users measuring their perception of the workspace and of mediation mechanisms that influence theirs cooperations with others.

The following exploratory mixed method design has enabled sufficient data collection with more detail than either qualitative or quantitative approaches would gen- 
erate separately. Using the said approach, quantitative data collection has been used to generalise the results of the central qualitative part of the study (Fuentes, 2008; Hesse-Biber, 2010). The qualitative component served to uncover various perspectives of sampled coworking environments. In contrast, the quantitative part made it possible to test the subjective view of the selected workspaces and generalise the results.

The core of the research is represented by a study of coworking spaces in Prague, the Czech Republic, using qualitative participant observations, supported by short open-ended interviews with community managers. The sample consisted of 13 coworking spaces in the nine months between March and November 2019.

Prague is one of the European Union's capital cities that is experiencing high economic growth (Sýkora, 2017), establishing itself as an entrepreneurial centre that is on par with major Western European cities and, most importantly, having a vibrant coworking ecosystem (Šindelářová and Kubíková, 2018). At the end of 2019, the Nomadlist, an online directory of international travellers working remotely worldwide, listed 133 work environments that have been identified as coworking offices, ${ }^{1}$ making Prague one of the prime pre-Covid-19 European locations to seek a coworking space (Nomadlist, n.d.) A recent study on growth factors of the coworking industry in Prague by Mayerhoffer (2020) has found that global coworking brands expand in Prague's metropolitan area by predominantly targeting corporate teams instead of users. Despite that, the local coworking spaces positively influence Prague's socio-economic situation. However, the fact of catering to the needs of mainly corporate teams puts to question the positive benefits of coworking space usage for independent users.

The selected coworking environments (see Table 1) have been chosen based on their popularity, reflected in the number of first-page hits when using a Google search with the combination of keywords "coworking space" and "Prague". Additionally, peer reviews have been checked to obtain an initial estimation of how these spaces are frequented and ensure a sufficient variety of selected places. All the chosen coworking spaces have been opened to the general public and have not been reserved for a particular target group (e.g., corporate teams, independent users, etc.)

Of the selected coworking spaces, nine were independent, meaning that they were single-location spaces and not a part of a larger enterprise. Four were part of a multinational franchise, having sister workspaces in other countries and cities worldwide. Six selected coworking spaces exceeded 500 sq. m, some occupying entire buildings and others crossing several floors. Five coworking spaces were mid-sized (between 100 and 500 sq. m), with the remaining two being smaller

\footnotetext{
${ }^{1}$ Other sources indicate more conservative estimates. Roussel (2018) has estimated that there are 15 coworking spaces in and around Prague, while Šindelářová \& Kubíková (2018) reported that there were 26 coworking environments within Prague's city limits. Contradictory numbers support the contention that a better classification of what is, or is not, a coworking space is warranted.
} 
than $100 \mathrm{sq}$. $\mathrm{m}$. The selected workspaces were mostly memberships based, meaning users paid a fee to access the coworking space for a given period of time (i.e., a day, a week or a month). Two sampled coworking environments had hybrid memberships that enabled free usage of a non-restricted area within the inner workspace (e.g., cafeteria). Still, they required a payment for complete access, while one workplace was entirely free of charge within the opening hours.

Table 1. Selected coworking sites

\begin{tabular}{|c|c|c|l|c|}
\hline $\begin{array}{c}\text { Work- } \\
\text { space }\end{array}$ & Size (sq. m) & $\begin{array}{c}\text { Workplace capacity } \\
\text { (individual sittings) }\end{array}$ & \multicolumn{1}{|c|}{ Access } & $\begin{array}{c}\text { Single location / } \\
\text { Multi-national }\end{array}$ \\
\hline A & $50-100$ & $1-50$ & Membership based & Single location \\
\hline B & $>500$ & $>100$ & Membership based & Multi-national \\
\hline C & $100-500$ & $50-100$ & Hybrid membership & Single location \\
\hline D & $>500$ & $>100$ & Membership based & Multi-national \\
\hline E & $100-500$ & $1-50$ & Free to use & Single location \\
\hline F & $100-500$ & $50-100$ & Membership based & Single location \\
\hline G & $100-500$ & $1-50$ & Hybrid membership & Single location \\
\hline H & $>500$ & $>100$ & Membership based & Single location \\
\hline I & $>500$ & $>100$ & Membership based & Single location \\
\hline J & $>500$ & $>100$ & Membership based & Multi-national \\
\hline K & $>500$ & $>100$ & Membership based & Multi-national \\
\hline L & $50-100$ & $1-50$ & Membership based & Single location \\
\hline M & $100-500$ & $1-50$ & Membership based & Single location \\
\hline
\end{tabular}

Source: own work.

The principal investigator (PI) spent approximately 25 hours in each selected coworking space as a casual workspace user, working on his daily work tasks while performing a non-obstructive participant observation. The PI's role and the research purpose have been revealed to the managers of selected coworking spaces. However, the process of non-obstructive participant observations has remained hidden to community managers and coworking space mediators to prevent interfering and possibly influencing the research process (e.g., by more actively working on community-based activities, interacting with other users, etc.) Upon the first visit, the researcher engaged in casual conversations with the daily community manager (9), baristas (3) and first impression manager/receptionist (1) that served as entry semi-structured interviews. While these interviews have mainly been unstructured for the most part to resemble an informal conversation that the said personnel would have with other users, three questions were included in all 13 cases: (1.) "Would 
you say that your coworking space has a supportive community (that I could benefit from)?"; (2.) "Does your coworking space support user encounters with spatial configuration and other tools?"; and (3.) "Are individuals reporting positive or negative effects that your coworking space has on them?"

After completing these semi-structured interviews, the selected coworking environments were used as a daily workplace by the PI. They were observed from two perspectives - spatial design, where the researcher observed the space and how it influenced the interaction of users within it (i.e., non-mediated and spontaneous activities), and human facilitation, where the observer noted interactions between individuals and the community-managers/mediators (i.e., mediated and planned activities). The usage of every work environment was flexible and was not attached to a specific sitting position so that the researcher frequently changed locations within the space (i.e., from shared flexible tables within the quiet parts of workspaces to working from the cafeteria section of the coworking environment). Notes were drafted in a paper-pencil form, pinpointing observations on three predictors and nine related observation points (see Table 2).

Table 2. Predictors and points of observation

\begin{tabular}{|c|c|}
\hline Predictors & Points of observation \\
\hline Spatial configuration & $\begin{array}{l}\text { (1a) Workspace layout } \\
\text { (1b) Furniture and workspace equipment } \\
\text { (1c) Presence of spatial mechanisms for accelerating } \\
\text { interaction between users }\end{array}$ \\
\hline Mediation mechanisms & $\begin{array}{l}\text { (2a) The existence of a mediation mechanism and related } \\
\text { tools } \\
\text { (2b) The presence and the role of mediators } \\
\text { (2c) Execution of mediation mechanisms } \\
\text { (2d) Organisational culture }\end{array}$ \\
\hline Frequency of interactions & $\begin{array}{l}\text { (3a) High/low frequency of interactions among users } \\
\text { (3b) High/low frequency of interactions between users and } \\
\text { community managers }\end{array}$ \\
\hline
\end{tabular}

Source: own work.

This approach provided the data which was analysed using Braun and Clarke's (2006) six-step analysis procedure. After identifying and analysing the problem, and collecting the sufficient entry data, thematic content analysis (Guest et al., 2011; Nowell et al., 2017; Terry et al., 2017) was used to categorise the selected workspaces based on (1) customised spatial configuration, (2) the presence and variety of mediation tools, and (3) how individuals used the selected coworking environment. The frequency of interactions was not directly measured but indirectly observed and estimated to assess the efficacy of spatial and human-mediated mechanisms subjectively. 
The findings which emerged based on the qualitative data collection and a subsequent analysis have been validated with a quantitative approach by completing a mean of 13.5 questionnaires with randomly selected daily workspace users, totalling 176 respondents. We need to note that the number of approached individuals has been adapted to the actual membership size of a selected coworking space. While the largest selected coworking space had more than a hundred users, the smallest workspace had as little as 20 full-time members. These short questionnaires were divided into three parts: the first part surveying the perceived presence of a supportive community within the space and the perceived presence of a community manager or mediator. The second part of the survey asked individuals to rate the formal and informal engagement of workspace staff. Workspace staff can have diverse approaches towards managing a supportive network, resulting in varying levels of community development. Therefore, to understand the types of vertical interactions that evolve between a workspace user and a community manager is pivotal if one wishes to understand a) the variety of mediation mechanisms that are being used, and b) the sort of interactions that develop within a particular class of a coworking space. The third and last part of the survey asked individuals how frequently they engaged in horizontal encounters with other workspace users. Understanding a workplace users' perspective about whether the coworking space has either a community or a manager who is steering relations within that space is crucial to perform a cross-comparison of the data that the qualitative part of the study had collected.

Before discussing the findings, it is essential to note that the authors have both founded and ran their coworking spaces (in two different CEE countries) and previously worked as community mediators. To add credibility to the conducted study, it is crucial to emphasise that the second author of this paper has been a co-founder and past owner of one of the coworking spaces where the research has been conducted (workspace F). However, the second author did not participate in the data collection or analysis of workspace $F$, mainly to avoid the possible conflict of interests or unintentionally influencing the results.

\section{FINDINGS}

\subsection{Uncovering themes}

The research revealed several subtypes of contemporary coworking environments. As anticipated, these spaces differ in terms of (1a) spatial configuration (closed/ semi-closed/open layout), (1b/1c) workspace equipment and functionality of the available furniture (workspace arrangement, various furniture for individual or collective use), $(2 \mathrm{a} / 2 \mathrm{~b} / 2 \mathrm{c})$ the presence of active and passive mediation mecha- 
nisms (i.e., tools to accelerate the interactions between coworking space users and that promote cooperation via networking and matchmaking processes), and (2d) specified organisational culture (i.e., established norms and expectations that predict and steer the behaviour of workspace users). The final observed differentiation, i.e. $(3 \mathrm{a} / \mathrm{b})$ the frequency of interaction between workspace users and between workspace users and community managers, relied on a subjective estimate by the investigating researcher but was not directly measured.

Analysis of the qualitative data revealed several differences between the sampled coworking spaces on the reoccurring themes. Table 3 shows the observed differentiating factors of the selected coworking spaces. It has been divided into four sections, with the first section reporting on the observed spatial configuration of a selected coworking space, the second outlining the observed presence of mediation mechanism, the third indicating the interactions that evolved during observations, and the final part summarising the apparent aims of a particular coworking space as reported by the workspace manager.

Four key thematic groups from the data follow. First, the observed workspaces were either open, partially open or closed to use for everyday users. While most of them had several membership packages, a handful of the observed coworking spaces were free-to-use during daily work hours. One of the space had a strict gatekeeping process that pushed individuals through several selection steps, while another was accessible by invitation-only.

Second, while coworking spaces are predominantly based on an open workspace design, they have various differentiating factors that influence user interactions. Four of the observed coworking environments had an open space divided into dedicated work, leisure, or social areas with different sitting configurations. Five of the workspaces had group worktables used either on a fixed basis (i.e., dedicated for the use of an individual) or a flexible one (i.e., non-dedicated work spot that anyone can use). Shared desks or - as observed in two cases - workstations with collaborative tools for precise mechanical work (e.g., 3D printers or technical devices) played an active role in promoting unprompted communication between workspace users.

For the most part, team-purposed coworking spaces not only reserved a selected number of work spots (via the fix desk system) but also divided open spaces with pane glass walls that enabled teams to have discrete work territories. Dividing the main workspace into subunits seems to produce limited encounters. However, four out of the thirteen coworking spaces had separate rest (e.g., café area) and leisure areas (e.g., game rooms) that helped overcome these restrictions and acted as non-guided mediation mechanisms promoting spontaneous and casual encounters between users. For example, eight workspaces had self-serving kitchen areas that enabled a homely feel to the workspace and increased sharing (e.g., coffee, tea, food, etc.) In contrast, other workspaces had bars with baristas acting as support personnel. Individual-purposed coworking spaces were less structured with fewer dedicated desks, promoting user circulation around the workspace. 


\begin{tabular}{|c|c|c|}
\hline 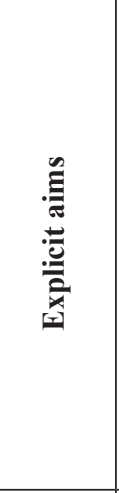 & 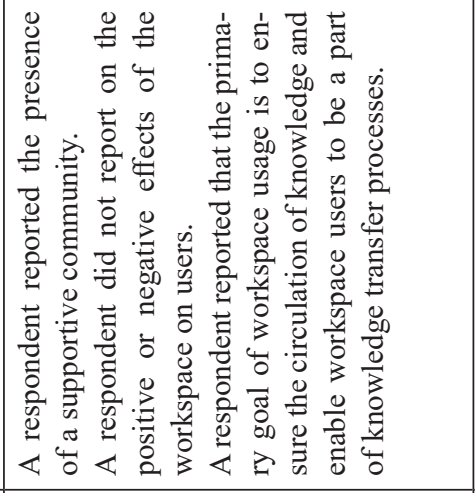 & 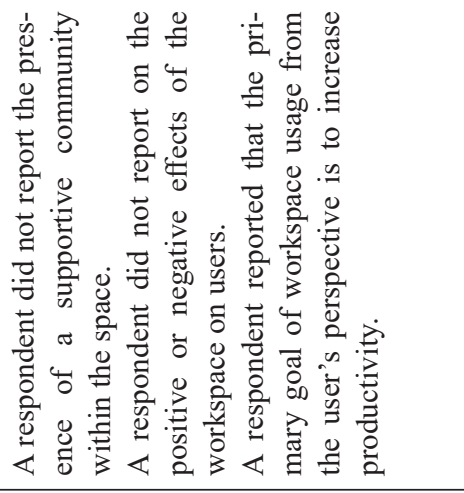 \\
\hline 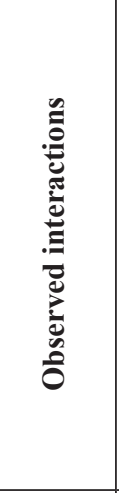 & 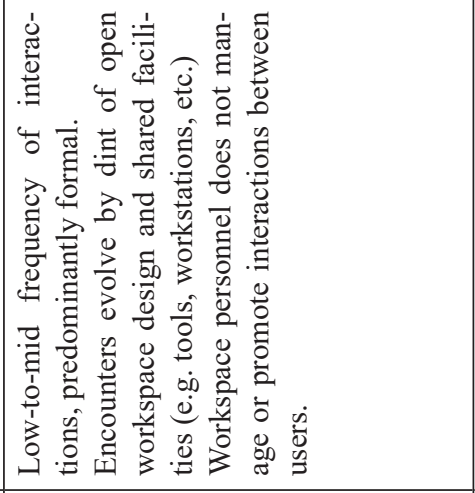 & 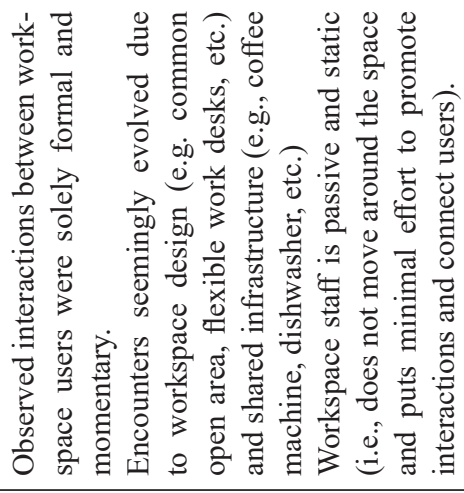 \\
\hline 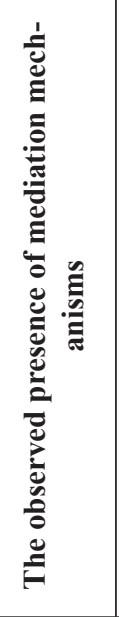 & 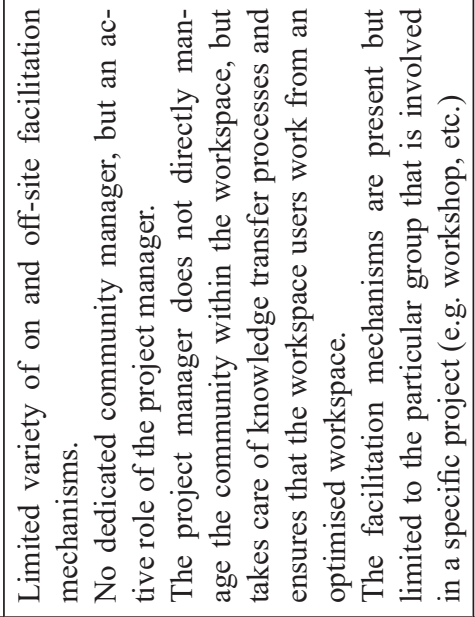 & 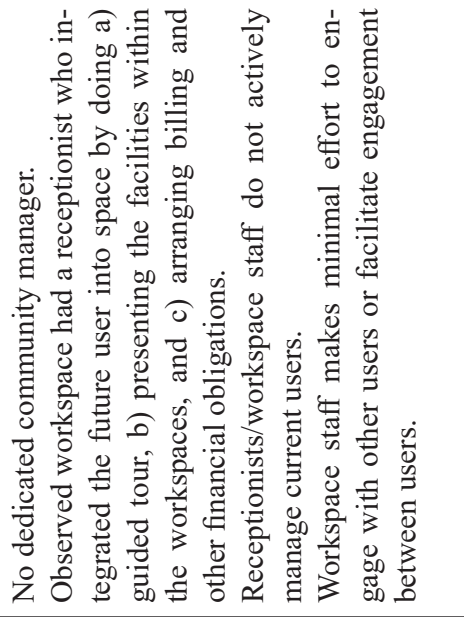 \\
\hline 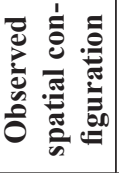 & 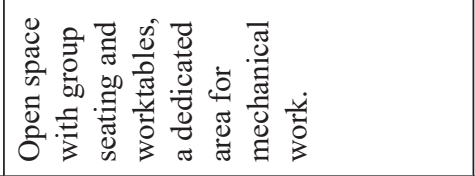 & 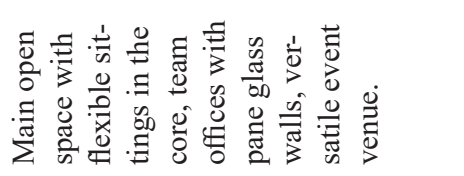 \\
\hline 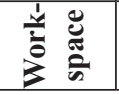 & $\ll$ & 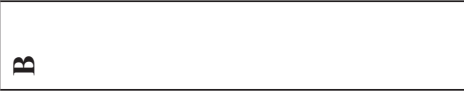 \\
\hline
\end{tabular}




\begin{tabular}{|c|c|}
\hline 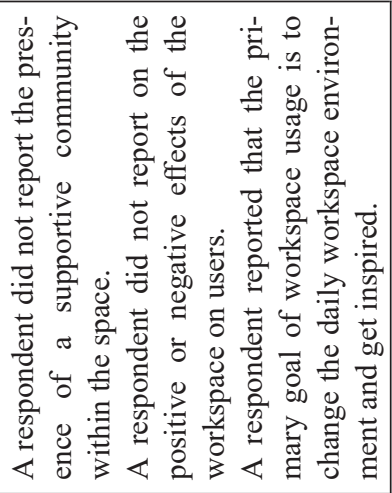 & 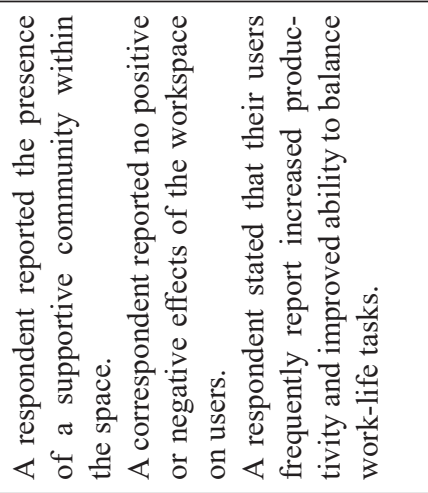 \\
\hline 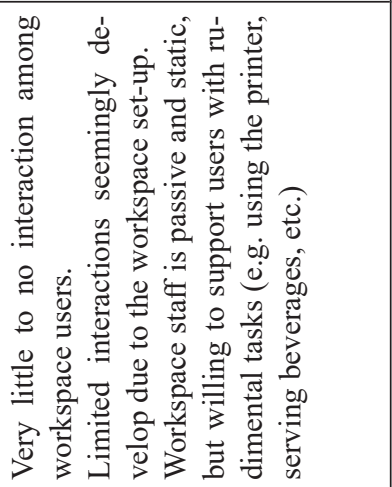 & 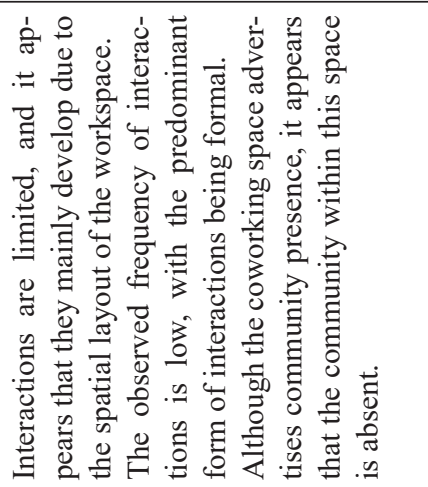 \\
\hline 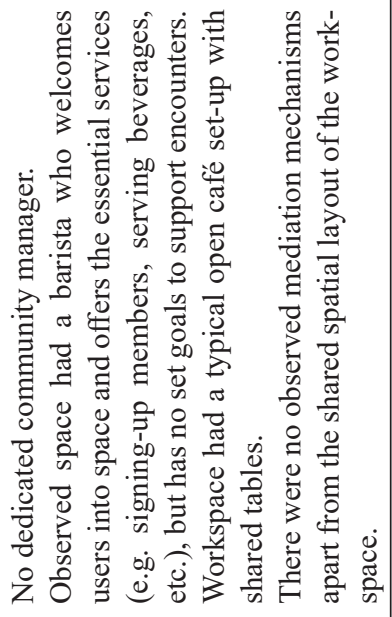 & 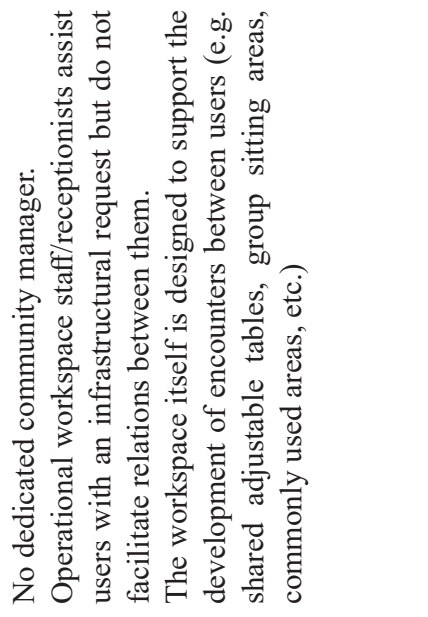 \\
\hline 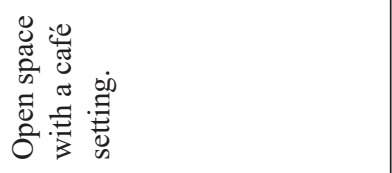 & 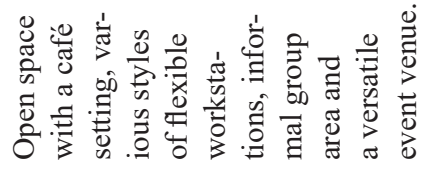 \\
\hline U & 0 \\
\hline
\end{tabular}




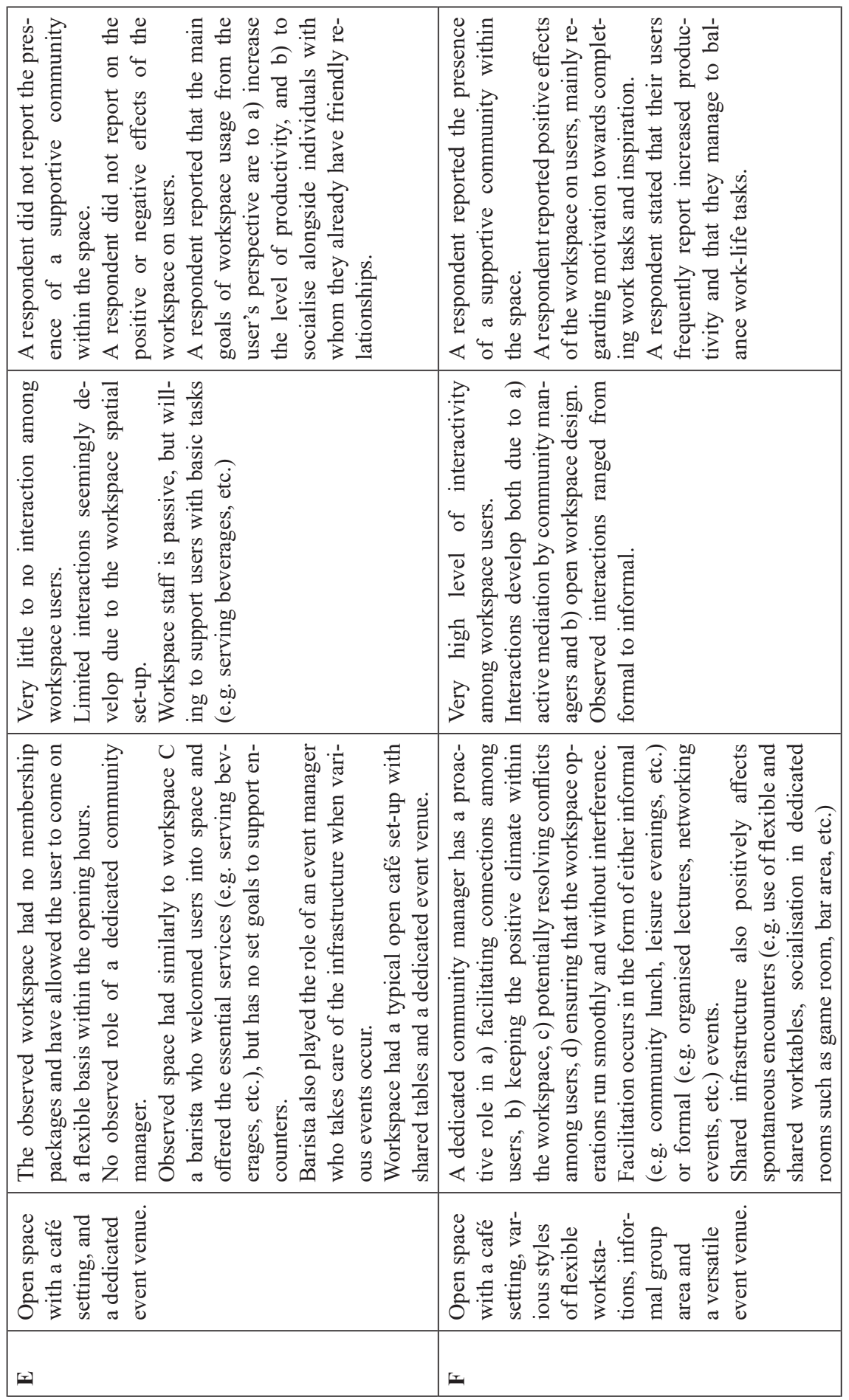




\begin{tabular}{|c|c|}
\hline 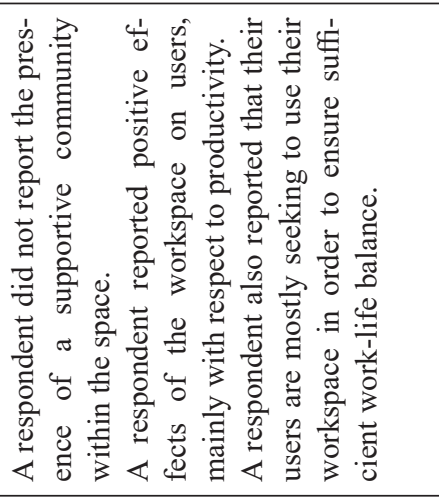 & 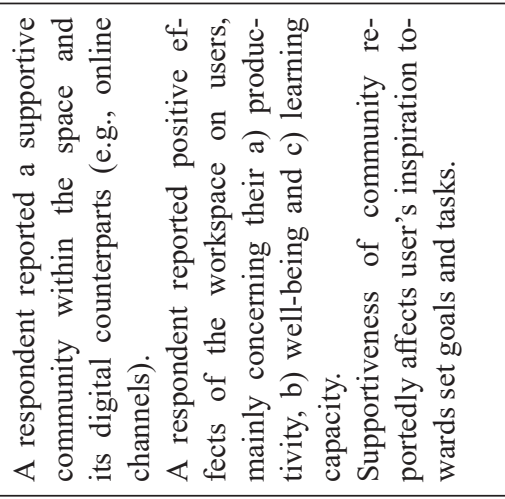 \\
\hline 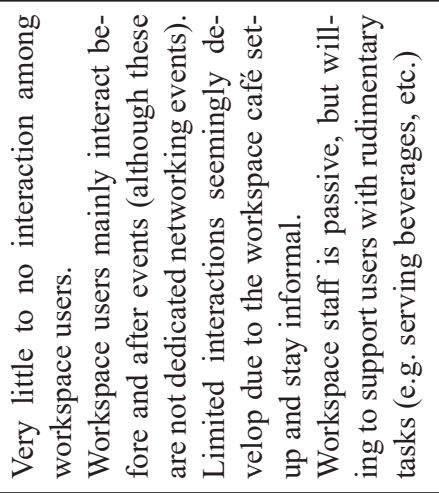 & 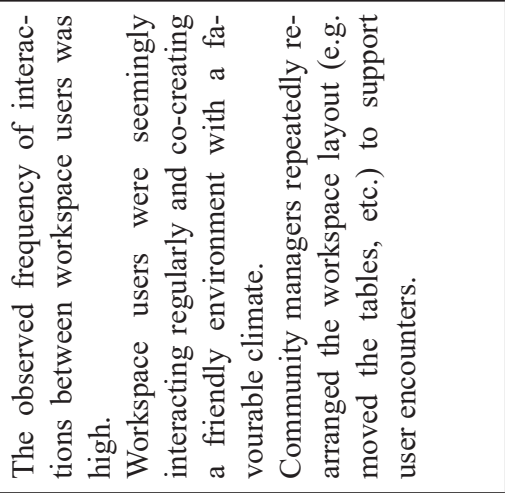 \\
\hline 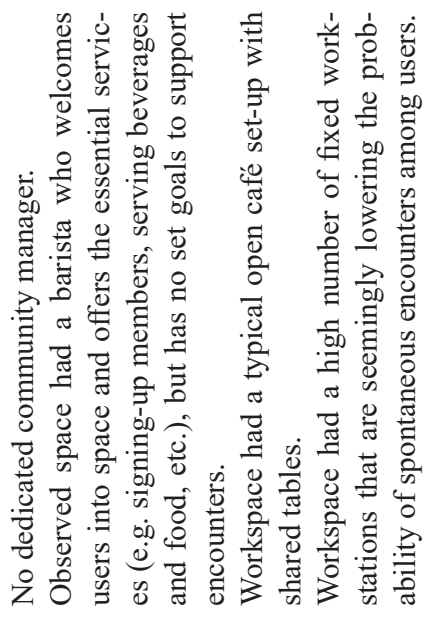 & 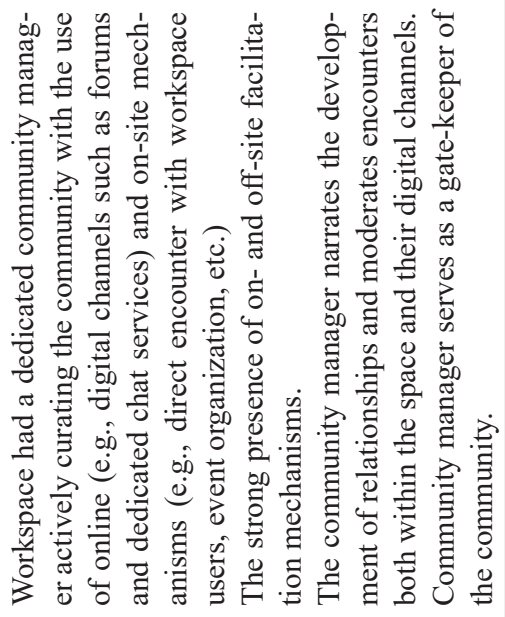 \\
\hline 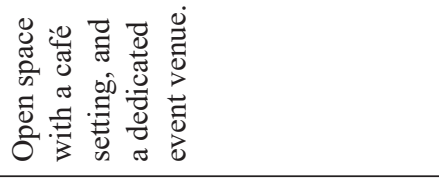 & 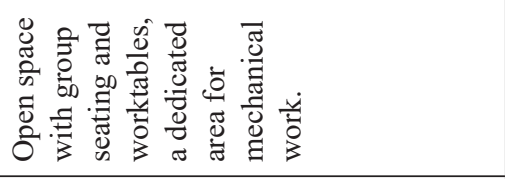 \\
\hline U & \pm \\
\hline
\end{tabular}




\begin{tabular}{|c|c|c|}
\hline 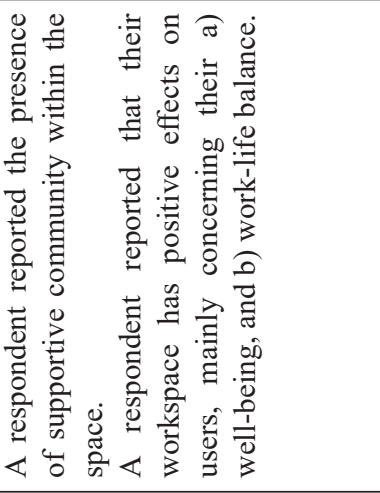 & 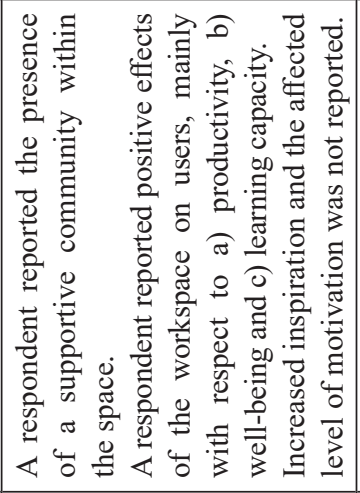 & 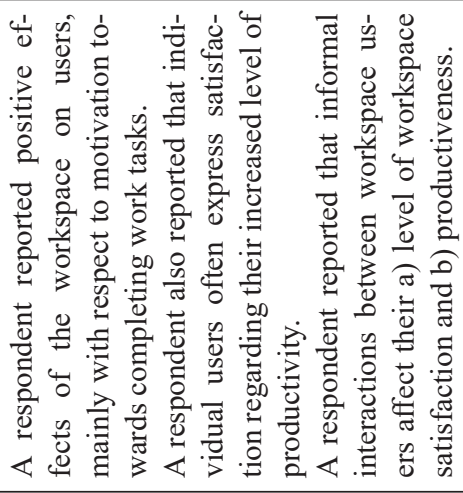 \\
\hline 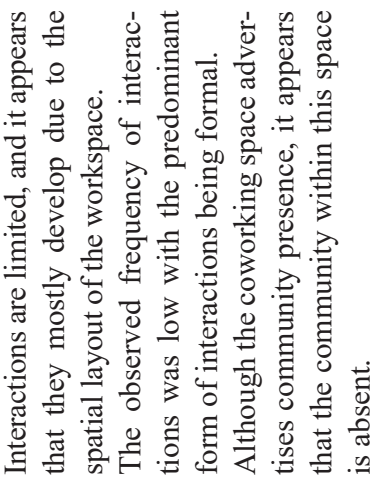 & 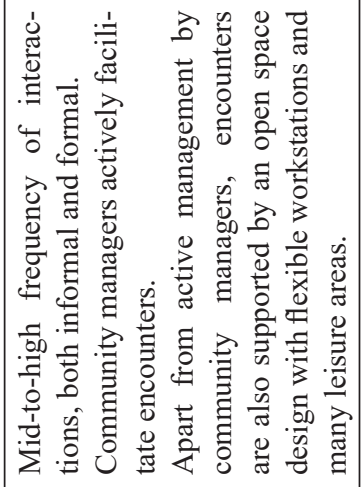 & 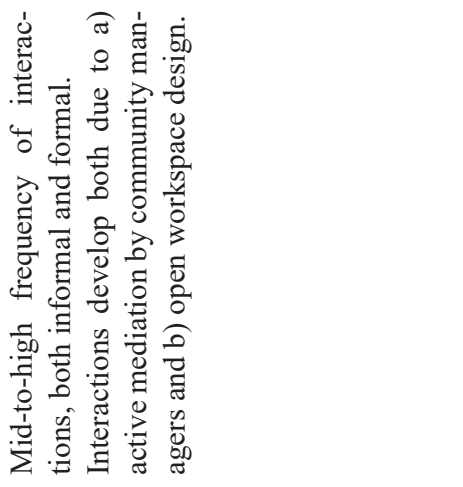 \\
\hline 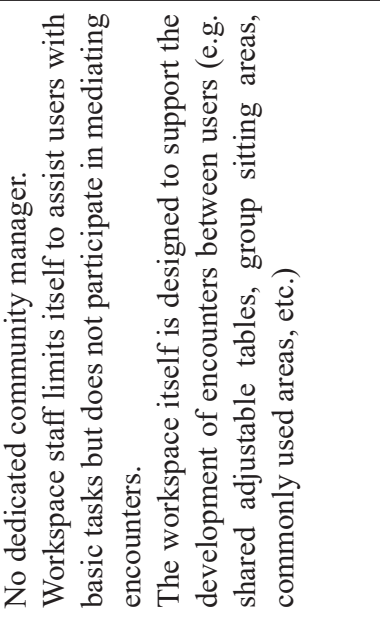 & 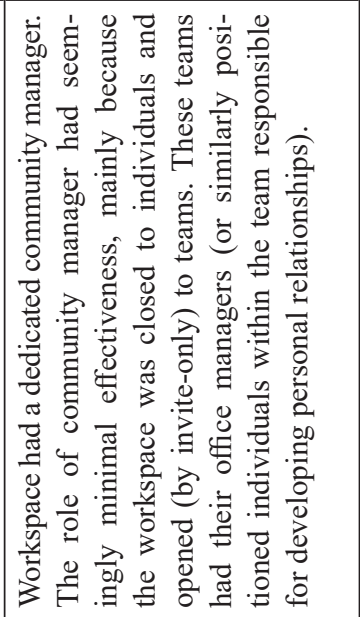 & 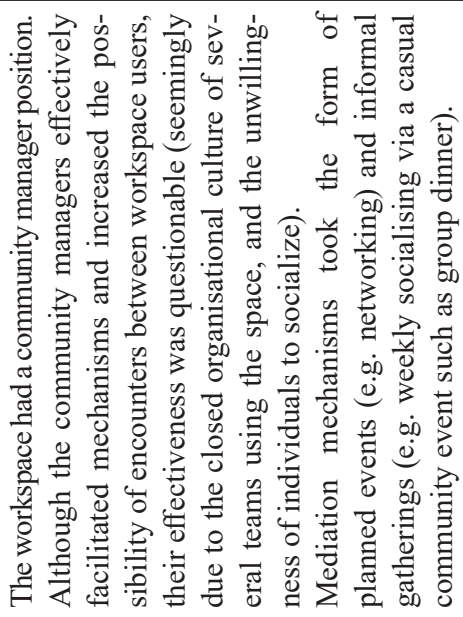 \\
\hline 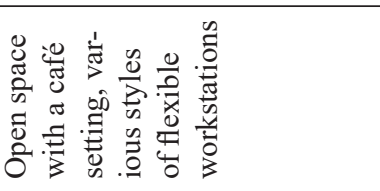 & 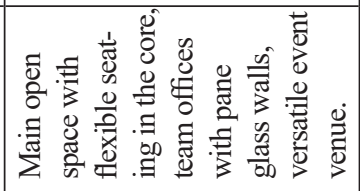 & 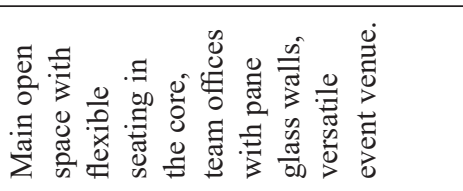 \\
\hline & & \\
\hline
\end{tabular}




\begin{tabular}{|c|c|}
\hline 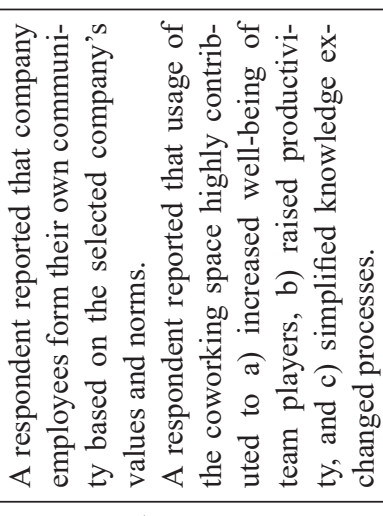 & 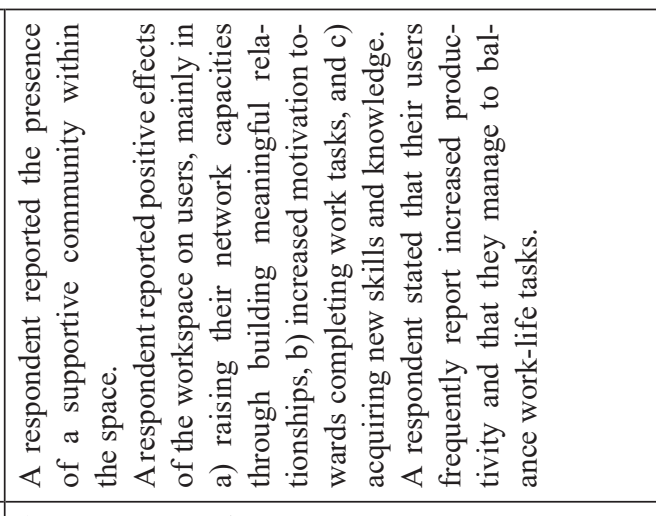 \\
\hline 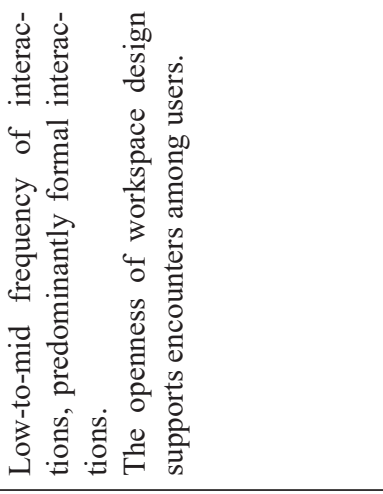 & 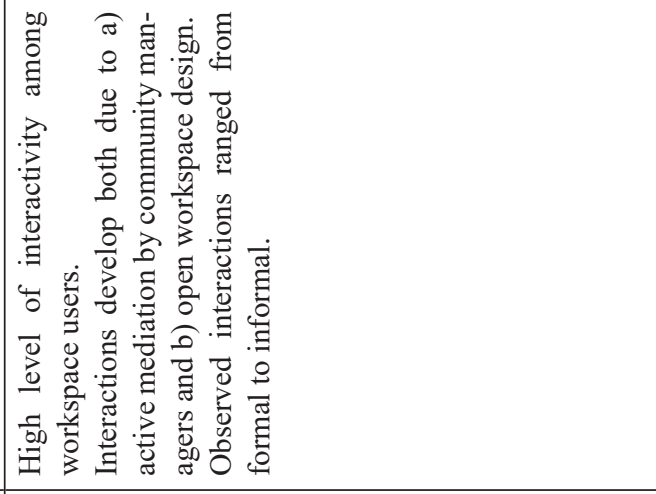 \\
\hline 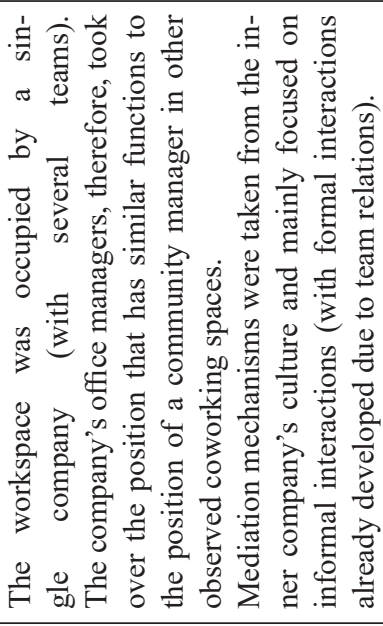 & 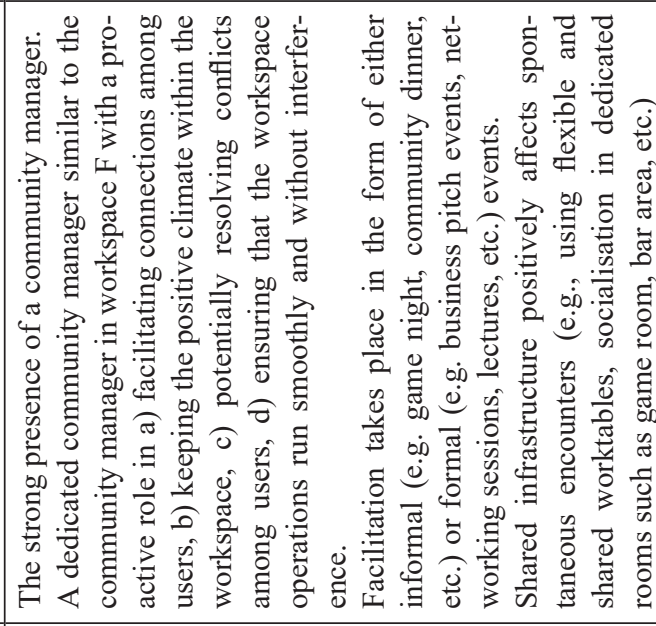 \\
\hline 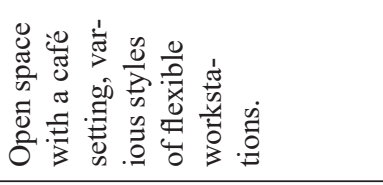 & 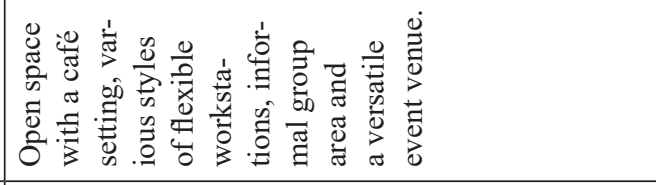 \\
\hline ב & $\Sigma$ \\
\hline
\end{tabular}


Third, the selected coworking environments gave workspace staff distinct roles. Some workspaces had dedicated community managers who were active in supporting the development of formal and informal interactions. In contrast, other spaces only had operational staff managing fundamental activities such as infrastructure maintenance, serving beverages or welcoming users to the workspace (e.g., project managers, receptionists or baristas). The level of active mediation, therefore, varied from workspace to workspace.

Fourth, the observed interactions varied widely across the observed spaces. The number of observed encounters was related to a) the presence and activeness of mediators (i.e., community managers), b) the keenness of their engagement towards formal (i.e., work-related) or informal (i.e., not work-related) interactions, and c) the design, purpose and openness of a coworking space. While formal interactions were more frequent in team-purposed coworking environments, informal interactions were more common in individual-purposed environments.

\subsection{Understanding differences}

It is vital to note that participant observation-only provided a limited and subjective assessment of the frequency of interactions, which enabled a rough estimate of differences. Furthermore, the stated aims from coworking space employees often contradicted the observations. In several cases, interviewed managers claimed a supportive community within their coworking space, while observations showed little to no interaction among workspace users. Since the interviews were framed in the context of the participant-observer visiting a space and deciding whether to work there, the discrepancy may reflect the unreliability of the respondent-employees, given that part of their role was presumably to sell the workspace to potential users. Table 4 summarises the reported communal aspects of selected coworking spaces.

The surveys of workspace users frequently contradicted the accounts by workspace managers. First, consider the perceived presence of a supportive community. All thirteen coworking spaces claimed, in conversations with their managers, to have a supportive community. Sampled users unanimously supported that position only in three of the sampled workspaces (where more than $90 \%$ of respondents said it was a supportive community) and marginally supported that claim in an additional three locations. In three locations, user responses were utterly mixed (with respondents supporting that claim between 50\% and 60\%). In the last four locations, user responses were decidedly negative, with fewer than one in four respondents endorsing the claim. These differences suggest not all "community-based" spaces are created equal, and-more importantly—not all coworking environments manage to create a sense of community at all. 


\begin{tabular}{|c|c|c|c|c|c|c|c|c|}
\hline 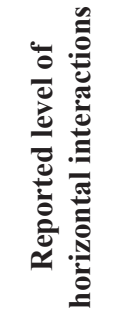 & 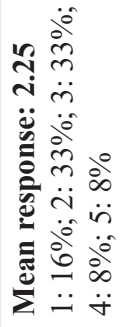 & 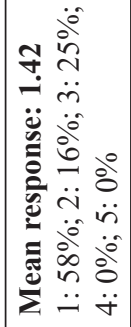 & 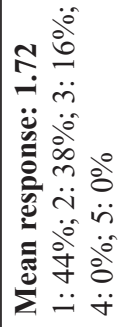 & 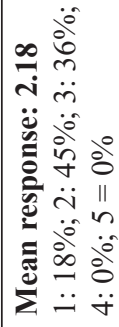 & 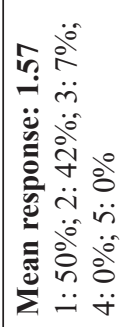 & 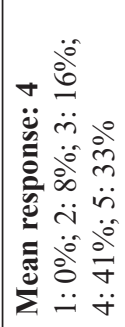 & 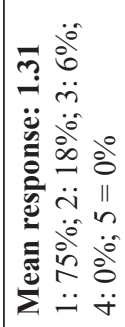 & 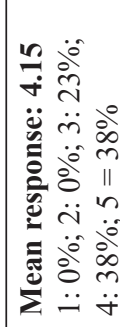 \\
\hline 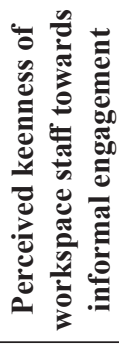 & 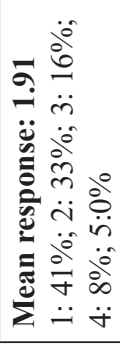 & 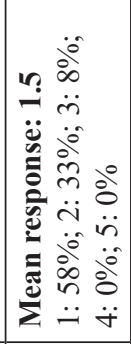 & 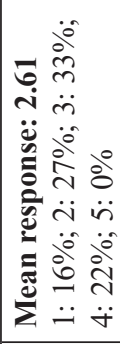 & 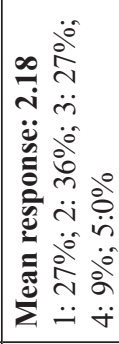 & 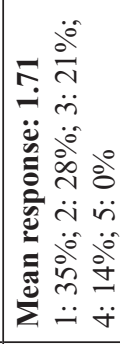 & 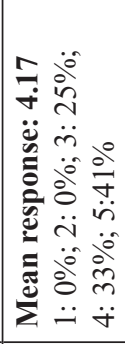 & 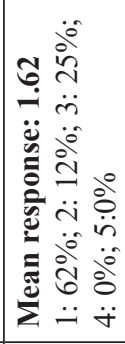 & 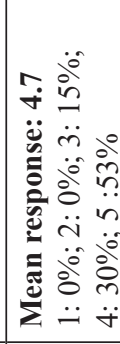 \\
\hline 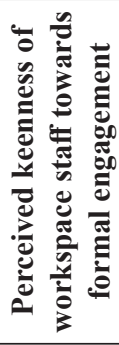 & 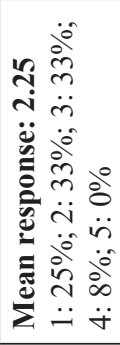 & 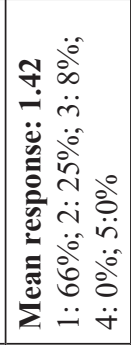 & 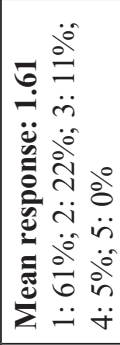 & 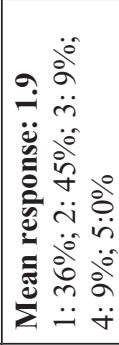 & 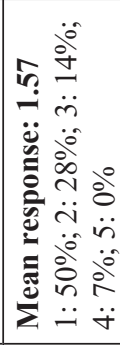 & 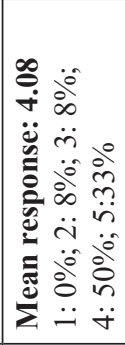 & 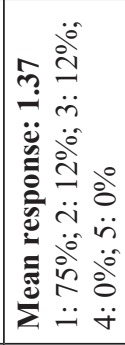 & 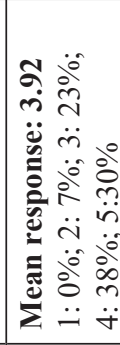 \\
\hline 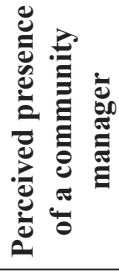 & 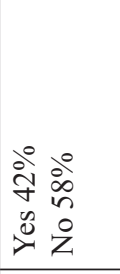 & $\begin{array}{ll}00 & \circ \\
\infty & \alpha \\
0 & 0 \\
\nu & z\end{array}$ & 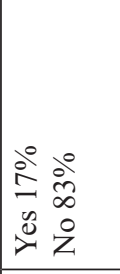 & 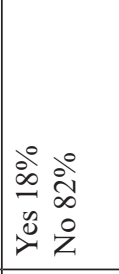 & 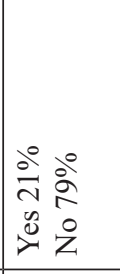 & 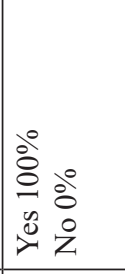 & $\begin{array}{ll}00 \\
0 & 0 \\
0 & 0 \\
0 & 0 \\
0 & z\end{array}$ & 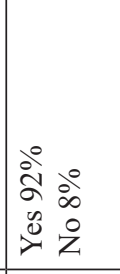 \\
\hline 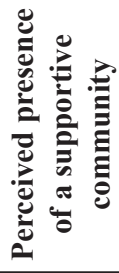 & 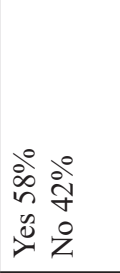 & 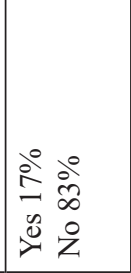 & 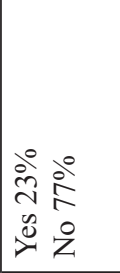 & 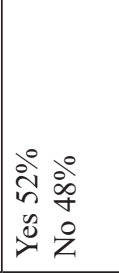 & 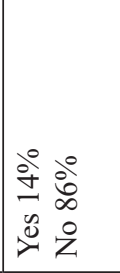 & 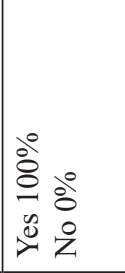 & 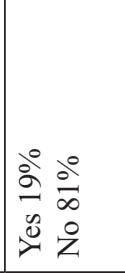 & 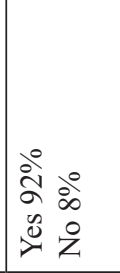 \\
\hline$=$ & $\approx$ & $\approx$ & $\infty$ & $\approx$ & \pm & $\approx$ & $\because$ & $\dddot{2}$ \\
\hline 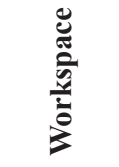 & $\varangle$ & $\varphi$ & $u$ & $\theta$ & II & $\omega$ & 0 & $I$ \\
\hline
\end{tabular}




\begin{tabular}{|c|c|c|c|c|c|}
\hline 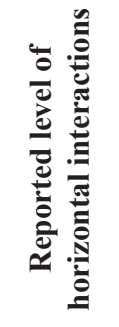 & 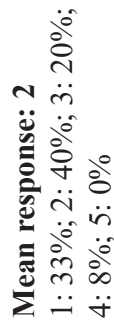 & 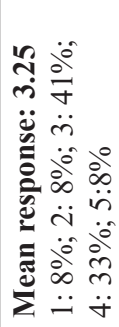 & 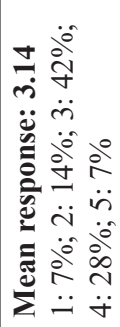 & 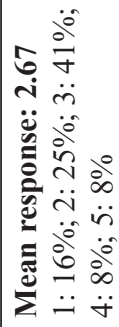 & 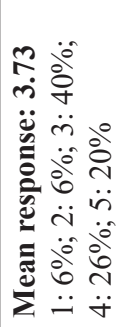 \\
\hline 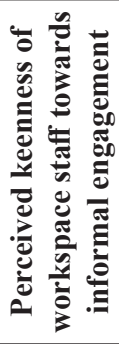 & 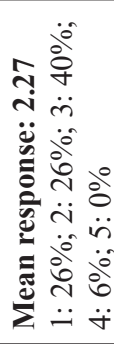 & 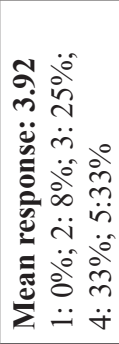 & 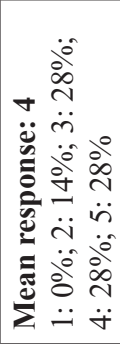 & 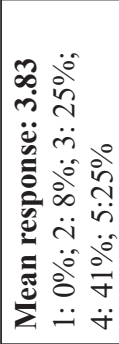 & 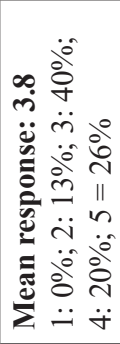 \\
\hline 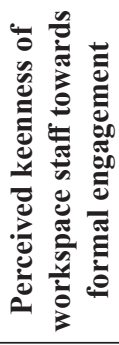 & 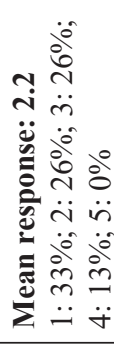 & 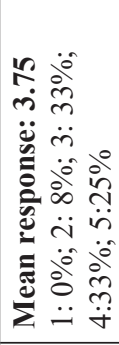 & 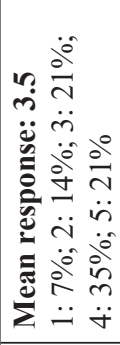 & 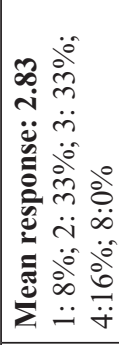 & 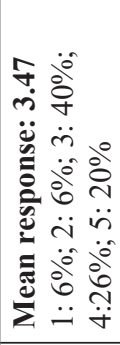 \\
\hline 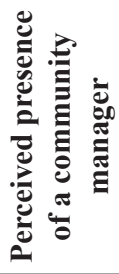 & 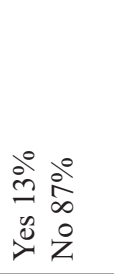 & 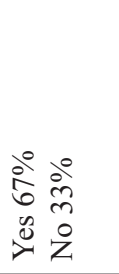 & 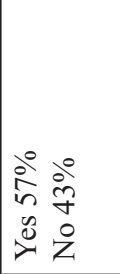 & 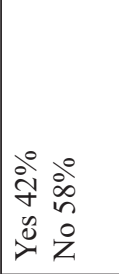 & 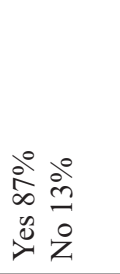 \\
\hline 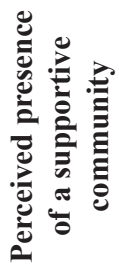 & 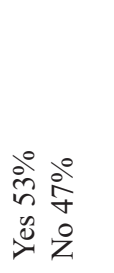 & 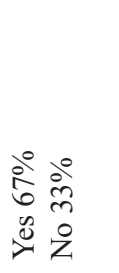 & 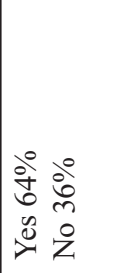 & 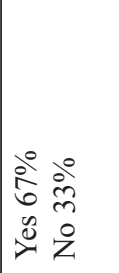 & 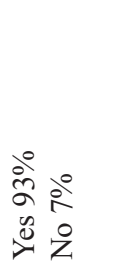 \\
\hline$=$ & 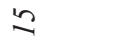 & $\approx$ & $\nabla$ & $\approx$ & $\cong$ \\
\hline 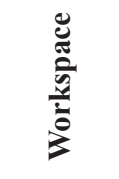 & $\neg$ & $r$ & $\forall$ & \lrcorner & $\Sigma$ \\
\hline
\end{tabular}


Similar findings emerged when measuring the perceived presence of a community manager. While six coworking spaces had dedicated community managers $(F, H, I, J, K$, and $M)$, the proactivity and effectiveness of those managers from the user perspective varied considerably. For example, while $100 \%$ of the respondents from coworking space $\mathrm{F}$ perceived the active presence of a community manager, only $13 \%$ of the respondents from space I perceived the existence of the same role. The discrepancy could also be seen in user responses regarding the keenness of workspace staff towards formal and informal engagement.

Coworking spaces with high rates of the perceived presence of a supportive community and the presence of community managers had high agreements in perceived keenness towards both types of encounters (e.g., workspace F). Nevertheless, it should be noted that the sampled users from two coworking spaces who did not report an active community manager and did not perceive the presence of a community still acknowledged the supportive role of workspace personnel towards informal encounters (workspaces $\mathrm{C}$ and I).

Finally, the reported level of horizontal interactions mostly confirmed the field observations. Coworking spaces with users who reported the presence of a supportive community and of a community manager keen to engage in both formal and informal encounters also featured high levels of horizontal interactions (i.e., between users and space managers; workspaces $\mathrm{F}, \mathrm{H}$, and $\mathrm{J}$ ). These interactions were not uncommon in coworking spaces without an active community manager but with the shared and open spatial design (workspaces A, I, and L). Even in these cases, however, the development of these interactions was related to active facilitation.

\section{CONCLUSION}

\subsection{Concluding discussion}

Based on a data comparison, we have been able to answer the first research question. Coworking spaces differ in terms of their spatial arrangements. Those arrangements influence horizontal interactions, whereby the openness of a workspace, and intentional workspace segmentation promote more interactions. Mediating mechanisms also play a crucial role in supporting formal and informal encounters on a horizontal and vertical levels. Therefore, the presence and activeness of mediation personnel are essential for developing a supportive community independent of spatial arrangements.

Nevertheless, quantitative data has shown that community mediators' presence and their manifested role do not necessarily correlate with workspace personnel's 
reported effectiveness. Some coworking spaces seemingly construct their community-building activities gradually over time and based on the proactive personalities of workspace mediators, while others mechanise and dehumanise the very same processes to produce instant communities.

While the research findings clearly show that contemporary coworking environments have morphed into multipurpose offices that are not necessarily community-based and may have a limited capacity to support horizontal interactions between workspace users, we cannot provide an intelligible answer to the second research question. It is understood that coworking has developed into a multidimensional workspace model that cannot stand by a singular definition. Significant differences in defining the factors of spatial design, the presence of mediation mechanisms, and the varying frequencies of both horizontal and vertical interactions that result in the development of a coworking community point towards the importance of taxonomising contemporary coworking spaces.

However, the sampling of a relatively small number of coworking spaces in one geographic region is insufficient to create a valid classification. As observed through the entry literature review, the coworking model has transformed from initially planned individual-based workspaces into predominantly team-based corporate offices with altering models in-between. Hence, we can only partially respond to the second research question and conclude that while most coworking spaces are based on developing communities that knit supportive relationships between workspace users, the actual execution may be questionable.

These findings indeed support the claim that coworking spaces often portray an image of community and collaboration principles while their workspaces in practice lack sufficient mediation support to steer encounters into the development of dynamic social networks of cooperation. Therefore, community washing appears common in the coworking industry, reinforcing a solid need to classify different coworking environments. Spatial configurations, the presence and effectiveness of mediations mechanisms, and the frequency of horizontal and vertical encounters could help classify the features of a future taxonomy of contemporary coworking spaces.

\subsection{Research limitations}

The research had its limitations mainly in the form of the non-responsiveness of coworking space users. The managers of coworking environments were approached directly upon the first use of a workspace. While all workspace managers approved the use of their premises to conduct the proposed research, not all gave consent to reveal the names of their workspaces. For that reason, the work environments were only generally described to enable the researchers to elaborate on their finding, but the identity of the workspaces have been maintained anonymous. 
Ethical concerns can be linked to the qualitative part of the research. Participants have been observed to reflect their habits of using a particular workspace, their affection by potential mediation mechanisms and workspace staff, and their interactions with each other. The role of the researcher was revealed to the managers of the observed workspaces, but the observation itself was unobstructed in order not to influence user daily routines. This risk was minimised by carefully protecting the anonymity of both workspace users and the coworking spaces themselves. Only aggregate data was shared so that individual workers could not be identified. These spaces were already accessible to other non-scholarly observers with similar relationships to the people being observed other than the motivation behind the observations, minimising the ethical implications. Furthermore, when presenting the questionnaires to workspace users, the research purpose was presented transparently and clearly.

One possible limitation of the conducted research is that the sample was taken entirely from one city. To the extent that coworking and other collaborative workspaces differ systematically across cities or countries (given their distinct languages, histories, and cultures), one concern is that these methods will uncover a community washing of Prague coworking spaces rather than a community washing of coworking spaces in general. As with any research, resources are limited, and we had to choose geographic constraints to make the scope of the research reasonable.

That said, there are many reasons to believe Prague is the ideal location for an initial study and that it will present a broad and mostly representative distribution of coworking spaces. As mentioned earlier, Prague has been recognised as a leading city in terms of the number and diversity of coworking spaces. One of the researchers has been actively involved in researching and developing coworking spaces in other countries around Europe and globally. From previous ethnographic work, he feels confident that Prague has a sufficiently wide distribution of spaces to understand coworking environments' defining features adequately. Finally, the sample of coworking spaces used for the study has intentionally been chosen to represent a diverse sample of collaborative open workspaces.

A second limitation of the research was that the questionnaires were entirely in English. One might object that the surveys should (also) be in the Czech language, and the fact of limiting them to English would limit and taint the sample. We were conscious of these objections when we were deciding to limit the surveys to English, which was made for a few reasons, both practical and theory-focussed. First, Prague-based coworking spaces are notable for their cross-cultural diversity. All the spaces we examined have a significant minority of non-Czech members, and some of them have a majority. Many non-Czechs in these spaces do not speak Czech, while most native Czech speakers (in these coworking spaces) are fluent in English. This was the reason for choosing English as the preferred language over Czech. But why not use multiple language versions of the survey? While it would be ideal to have a survey in the native language of every participant translated 
in such a way as to maintain meaning across distinct languages correctly, this ideal would, of course, not be possible in practice. Every translation necessarily changes the meaning of the questions, and so a Czech version of the English survey could do more to taint the responses than giving the same English version to Czech speakers fluent in English. As we intended to provide the same survey not just to native Czech and native English speakers, but primarily to non-native English speakers from many, many countries, the quality of the responses would be as good as that of the questions asked. This reminded us to be careful in creating the questions and response categories that were direct and difficult to misinterpret. We believe it has resulted in higher quality and more directly comparable responses.

\section{REFERENCES}

AGUITON, C. and CARDON, D. (2008), 'Barcamps and coworking: Collective web-based infrastructures for innovation', Hermès, La Revue, (1), pp. 75-82. https://doi.org/10.4267/2042/24155

AKHAVAN, M., MARIOTTI, I., ASTOLFI, L. and CANEVARI, A. (2019), 'Coworking Spaces and New Social Relations: A Focus on the Social Streets in Italy', Urban Science, 3 (1), pp. 2-11. https://doi.org/10.3390/urbansci3010002

ARORA, S. (2017), 'Changing dynamics of corporate real estate: The rise of coworking spaces', Corporate Real Estate Journal, 7 (2), pp. 127-136.

AVDIKOS, V. and ILIOPOULOU, E. (2019), 'Community-Led Coworking Spaces: From Co-location to Collaboration and Collectivisation', [in:] GILL, R., PRATT A. and VIRANI, T. (eds.), Creative Hubs in Question. Dynamics of Virtual Work, pp. 111-129, Cham: Palgrave Macmillan. https://doi.org/10.1007/978-3-030-10653-9_6

AVRAM, G., CHOI, J. H. J., De PAOLI, S., LIḠHT, A., LYLE, P. and TELI, M. (2017), 'Collaborative economies: From sharing to caring', [in:] Proceedings of the 8th International Conference on Communities and Technologies, pp. 305-307, ACM. https://doi.org/10.1145/3083671.3083712

BIANCHI, F., CASNICI, N. and SQUAZZONI, F. (2018), 'Solidarity as a by-product of professional collaboration: social support and trust in a coworking space', Social Networks, 54, pp. 61-72. https://doi.org/10.1016/j.socnet.2017.12.002

BLAGOEV, B., COSTAS, J. and KÄRREMAN, D. (2019), '«We are all herd animals»: Community and organizationality in coworking spaces', Organisation, 26 (6), pp. 894-916. https://doi. org $/ 10.1177 / 1350508418821008$

BOUNCKEN, R. B. and REUSCHL, A. J. (2018), 'Coworking-spaces: how a phenomenon of the sharing economy builds a novel trend for the workplace and for entrepreneurship', Review of Managerial Science, 12 (1), pp. 317-334. https://doi.org/10.1007/s11846-016-0215-y

BOUNCKEN, R. B., LAUDIEN, S. M., FREDRICH, V. and GÖRMAR, L. (2018), 'Coopetition in coworking-spaces: value creation and appropriation tensions in an entrepreneurial space', Review of Managerial Science, 12 (2), pp. 385-410. https://doi.org/10.1007/s11846-017-0267-7

BOUNCKEN, R. and ASLAM, M. M. (2019), 'Understanding knowledge exchange processes among diverse users of coworking-spaces', Journal of Knowledge Management. https://doi. org/10.1108/JKM-05-2018-0316

BRAUN, V. and CLARKE, V. (2006), 'Using thematic analysis in psychology', Qualitative Research in Psychology, 3 (2), pp. 77-101. https://doi.org/10.1191/1478088706qp063oa

BROWN, J. (2017), 'Curating the "Third Place»? Coworking and the mediation of creativity', Geoforum, 82, pp. 112-126. https://doi.org/10.1016/j.geoforum.2017.04.006 
BUENO, S., RODRÍGUEZ-BALTANÁS, G. and GALlEGO, M. D. (2018), 'Coworking spaces: A new way of achieving productivity', Journal of Facilities Management, 16 (4), pp. 452-466. https://doi.org/10.1108/JFM-01-2018-0006

BUTCHER, T. (2018), 'Learning everyday entrepreneurial practices through coworking', Management Learning, 49 (3), pp. 327-345. https://doi.org/10.1177/1350507618757088

CABRAL, V. and Van WINDEN, W. (2016), 'Coworking: an analysis of coworking strategies for interaction and innovation', International Journal of Knowledge-Based Development, 7 (4), p. 357. https://doi.org/10.1504/IJKBD.2016.10001777

CAPDEVILA, I. (2014), 'How can city labs enhance the citizens' motivation in different types of innovation activities?', [in:] AIELLO, L. and MCFARLAND, D. (eds.), International Conference on Social Informatics, pp. 64-71, Cham: Springer. https://doi.org/10.1007/978-3-319-15168-7_9

CASTILHO, M. F. and QUANDT, C. O. (2017), 'Collaborative Capability in Coworking Spaces: Convenience Sharing or Community Building?', Technology Innovation Management Review, 7 (12), pp. 32-42. https://doi.org/10.22215/timreview/1126

CHEAH, S. and HO, Y. P. (2019), 'Coworking and Sustainable Business Model Innovation in Young Firms', Sustainability, 11 (10), pp. 29-59. https://doi.org/10.3390/su11102959

CONSTANTINESCU, T. and DEVISCH, O. (2018), 'Portraits of work: mapping emerging coworking dynamics', Information, Communication \& Society, 21 (9), pp. 1263-1278. https://doi.org/ 10.1080/1369118X.2018.1459775

De PEUTER, G., COHEN, N. S. and SARACO, F. (2017), 'The ambivalence of coworking: On the politics of an emerging work practice', European Journal of Cultural Studies, 20 (6), pp. 687706. https://doi.org/10.1177/1367549417732997

FUENTES, C. M. M. (2008), 'Pathways from interpersonal violence to sexually transmitted infections: A mixed-method study of diverse women', Journal of women's health, 17 (10), pp. 15911603. https://doi.org/10.1089/jwh.2008.0885

FUZI, A., GRYSZKIEWICZ, L. and SIKORA, D. (2018), 'A Spectrum of Urban Innovation Intermediaries: from Coworking to Collaboration', [in:] ISPIM Conference Proceedings, pp. 1-6, The International Society for Professional Innovation Management (ISPIM).

GANDINI, A. (2016), 'Coworking: The Freelance Mode of Organisation?' [in:] The Reputation Economy, pp. 97-105, London: Palgrave Macmillan. https://doi.org/10.1057/978-1-137-56107-7_7

GARRETT, L. E., SPREITZER, G. M. and BACEVICE, P. A. (2017), 'Co-constructing a sense of community at work: The emergence of community in coworking spaces', Organisation Studies, 38 (6), pp. 821-842. https://doi.org/10.1177/0170840616685354

GAUGER, F., STRYCH, J. O. and PFNÜR, A. (2019), The link between coworking space demand and venture capital financing: Empirical evidence from European office market (No. eres2019_170). European Real Estate Society (ERES).

GERDENITSCH, C., SCHEEL, T. E., ANDORFER, J. and KORUNKA, C. (2016), 'Coworking spaces: A source of social support for independent professionals', Frontiers in Psychology, 7, pp. 1-12. https://doi.org/10.3389/fpsyg.2016.00581

GREEN, R. (2014), 'Collaborate or compete: how do landlords respond to the rise in coworking?', Cornell Real Estate Review, 12 (1), p. 9.

GREGG, M. and LODATO, T. (2018), 'Managing community: Co working, hospitality and the future of work', [in:] RÖTTGER-RÖSSLER, B. and SLABY, J. (eds.), Affect in Relation. Families, Places, Technologies, pp. 175-196, London: Routledge. https://doi.org/10.4324/9781315163864-9

GUEST, G., MACQUEEN, K. M. and NAMEY, E. E. (2012), Applied thematic analysis, SAGE Publications. https://doi.org/10.4135/9781483384436

HALL, G., SIGALA, M., RENTSCHLER, R. and BOYLE, S. (2019), 'Motivations, Mobility and Work Practices; The Conceptual Realities of Digital Nomads', [in:] Information and Communication Technologies in Tourism, 2019, pp. 437-449, Cham: Springer. 
HAUBRICH, G. F. (2021), 'Mediation Matters: The Role of Staff in Coworking Constitution', [in:] OREL, M., DVOULETÝ, O. and RATTEN, V. (eds), The Flexible Workplace. Human Resource Management, pp. 157-172, Cham: Springer. https://doi.org/10.1007/978-3-030-62167-4_9

HAWLITSCHEK, F., STOFBERG, N., TEUBNER, T., TU, P. and WEINHARDT, C. (2018), 'How corporate sharewashing practices undermine consumer trust', Sustainability, 10 (8), p. 2638. https://doi.org/10.3390/su10082638

HESSE-BIBER, S. (2010), 'Qualitative approaches to mixed methods practice', Qualitative inquiry, 16 (6), pp. 455-468. https://doi.org/10.1177/1077800410364611

HILL, A. (2019), 'Companies beware the cult of community', https://www.ft.com/content/ee5fa6aac424-11e9-ae6e-a26d1d0455f4 [accessed on: 29.11.2019].

KOVÁCS, J. K. and ZOLTÁN, E. S. (2017), 'Rural enterprise hub supporting rural entrepreneurship and innovation-case studies from Hungary', European Countryside, 9 (3), pp. 473-485. https:// doi.org/10.1515/euco-2017-0028

KUBÁTOVÁ, J. (2014), 'The cause and impact of the development of coworking in the current knowledge economy', [in:] Proceedings of the 15th European Conference on Knowledge Management, Santarem, Portugal, pp. 4-5.

LECLERCQ-VANDELANNOITTE, A. and ISAAC, H. (2016), 'The new office: how coworking changes the work concept', Journal of Business Strategy, 37 (6), 3-9. https://doi.org/10.1108/ JBS-10-2015-0105

LUKMAN, Y. A., EKOMADYO, A. S. and WIBOWO, A. S. (2018), 'Assembling the Past and the Future of the City through Designing Coworking Facilities', [in:] IOP Conference Series: Earth and Environmental Science, 158 (1), p. 012051, IOP Publishing. https://doi.org/10.1088/1755$1315 / 158 / 1 / 012051$

LUMLEY, R. M. (2014), 'A coworking project in the campus library: supporting and modeling entrepreneurial activity in the academic library', New Review of Academic Librarianship, 20 (1), pp. 49-65. https://doi.org/10.1080/13614533.2013.850101

MARCHEGIANI, L. and ARCESE, G. (2018), 'Collaborative spaces and coworking as hybrid workspaces: friends or foes of learning and innovation?' [in:] BOCCARDELLI, P., ANNOSI, M., BRUNETTA, F. and MAGNUSSON, M. (eds.), Learning and Innovation in Hybrid Organizations, pp. 51-71, Cham: Palgrave Macmillan. https://doi.org/10.1007/978-3-319-62467-9_4

MAYERHOFFER, M. (2020), 'Growth factors of the coworking industry: the case of Prague', Journal of Property Investment \& Finance. https://doi.org/10.1108/JPIF-12-2019-0164

MERKEL, J. (2015), 'Coworking in the city', Ephemera, 15 (2), pp. 121-139.

MERKEL, J. (2019), 'Curating Strangers', [in:] GILL, R., PRATT, A. and VIRANI, T. (eds.), Creative Hubs in Question. Dynamics of Virtual Work, pp. 51-68, Cham: Palgrave Macmillan. https://doi.org/10.1007/978-3-030-10653-9_3

MIREL, D. (2015), 'Redefining the work place: as collaborative cowork spaces continue to gain popularity, these progressive office spaces are creating their own unique personalities to draw in members', Journal of Property Management, 80 (4), pp. 48-55.

NAGY, G. and GREG, L. (2018), 'Why Companies Are Creating Their Own Coworking Spaces', Harvard Business Review online.

Nomadlist. (n.d), [Nomadlist directory for coworking spaces in Prague, Czech Republic]. https:// nomadlist.com/coworking/prague [accessed on: 4.11.2019].

NOWELL, L. S., NORRIS, J. M., WHITE, D. E. and MOULES, N. J. (2017), 'Thematic analysis: Striving to meet the trustworthiness criteria', International Journal of Qualitative Methods, 16 (1), pp. 1-13. https://doi.org/10.1177/1609406917733847

OREL, M. (2019), 'Supporting work-life balance with the use of coworking spaces', Equality, Diversity and Inclusion: An International Journal, 39 (5), pp. 549-565. https://doi.org/10.1108/ EDI-01-2019-0038 
OREL, M. and ALONSO ALMEIDA, M. D. M. (2019), 'The ambience of collaboration in coworking environments', Journal of Corporate Real Estate, 21 (4), pp. 273-289. https://doi. org/10.1108/JCRE-12-2018-0050

OREL, M. and DVOULETÝ, O. (2020), 'Transformative changes and developments of the coworking model: A narrative review', [in:] RATTEN, V. (ed.), Technological Progress, Inequality and Entrepreneurship. Studies on Entrepreneurship, Structural Change and Industrial Dynamics, pp. 9-27, Cham: Springer. https://doi.org/10.1007/978-3-030-26245-7_2

PARRINO, L. (2015), 'Coworking: assessing the role of proximity in knowledge exchange', Knowledge Management Research \& Practice, 13 (3), pp. 261-271. https://doi.org/10.1057/ kmrp.2013.47

PENZ, E., HARTL, B. and HOFMANN, E. (2018), 'Collectively Building a Sustainable Sharing Economy Based on Trust and Regulation', Sustainability, 10 (10), pp. 1-6. https://doi. org/10.3390/su10103754

PRICE, L. L. and BELK, R. W. (2016), 'Consumer ownership and sharing: Introduction to the issue', Journal of the Association for Consumer Research, 1 (2), pp. 193-197. https://doi. org/10.1086/686270

ROUSSEL, P. (2016), 'Coworking cities in Prague', https://medium.com/coworking-people-spaces/13-coworking-cities-prague-8a376e96931a [accessed on: 4.11.2019].

ROSATI, U. and CONTI, S. (2016), 'What is a smart city project? An urban model or a corporate business plan?', Procedia-Social and Behavioral Sciences, 223, pp. 968-973. https://doi. org/10.1016/j.sbspro.2016.05.332

ROSS, P. and RESSIA, S. (2015), 'Neither office nor home: Coworking as an emerging workplace choice', Employment Relations Record, 15 (1), pp. $42-57$.

RUS, A. and OREL, M. (2015), 'Coworking: a community of work', Teorija in Praksa, 52 (6), pp. 1017-1038.

SARGENT, K., COOPER, J., MELLWIG, B. and MCDONALD, M. (2018), 'Coworking and the disruption of the current corporate real estate model', Corporate Real Estate Journal, 7 (3), pp. 267-276.

SCHMIDT, S., BRINKS, V. and BRINKHOFF, S. (2014), 'Innovation and creativity labs in Berlin', Zeitschrift für Wirtschaftsgeographie, 58 (1), pp. 232-247. https://doi.org/10.1515/ zfw.2014.0016

SCHOPFEL, J., ROCHE, J. and HUBERT, G. (2015), 'Coworking and innovation: new concepts for academic libraries and learning centres', New Library World, 116 (1/2), pp. 67-78. https://doi. org/10.1108/NLW-06-2014-0072

SCHOR, J. (2016), 'Debating the sharing economy', Journal of Self-Governance and Management Economics, 4 (3), pp. 7-22. https://doi.org/10.22381/JSME4320161

SPINUZZI, C. (2012), 'Working alone together: Coworking as emergent collaborative activity', Journal of Business and Technical Communication, 26 (4), pp. 399-441. https://doi. org/10.1177/1050651912444070

SPINUZZI, C., BODROŽIĆ, Z., SCARATTI, G. and IVALDI, S. (2019), “«Coworking Is About Community»: But What Is «Community» in Coworking?', Journal of Business and Technical Communication, pp. 112-140. https://doi.org/10.1177/1050651918816357

SURMAN, T. (2013), 'Building social entrepreneurship through the power of coworking', Innovations: Technology, Governance, Globalization, 8 (3-4), pp. 189-195. https://doi.org/10.1162/ INOV_a_00195

SÝKORA, L. (2017), 'Urban development, policy and planning in the Czech Republic and Prague', [in:] ALTROCK, U., GÜNTNER, S. and PETERS, D., Spatial Planning and Urban Development in the New EU Member States, pp. 127-154, London: Routledge.

ŠINDELÁŘOVÁ, L. and KUBÍKOVÁ, P. (2018), Coworking in The Czech Republic, BNP Paribas Real Estate Report. 
TERRY, G., HAYFIELD, N., CLARKE, V. and BRAUN, V. (2017), 'Thematic analysis', The SAGE handbook of qualitative research in psychology, 2, pp. 17-37. https://doi. org/10.4135/9781526405555.n2

WATERS-LYNCH, J. and POTTS, J. (2017), 'The social economy of coworking spaces: a focal point model of coordination', Review of Social Economy, 75 (4), pp. 417-433. https://doi.org/1 0.1080/00346764.2016.1269938

WEIJS-PERRÉE, M., van de KOEVERING, J., APPEL-MEULENBROEK, H. A. J. A., and ARENTZE, T. A. (2017), 'User preferences for coworking space characteristics', [in:] 24th Annual European Real Estate Society Conference (ERES 2017), pp. 145-162. https://doi. org/10.15396/eres2017_88

YANG, E., BISSON, C. and SANBORN, B. E. (2019), 'Coworking space as a third-fourth place: changing models of a hybrid space in corporate real estate', Journal of Corporate Real Estate, 21 (4), pp. 324-345. https://doi.org/10.1108/JCRE-12-2018-0051 